\title{
Peroxidase production from hairy root cultures of red beet (Beta vulgaris)
}

\author{
Thimmaraju Rudrappa \\ Plant Cell Biotechnology Department \\ Central Food Technological Research Institute \\ Mysore - 570 020, India \\ Tel: 918212516502 \\ Fax: 918212517233 \\ E-mail: rajurt@yahoo.com \\ Bhagyalakshmi Neelwarne* \\ Plant Cell Biotechnology Department \\ Central Food Technological Research Institute \\ Mysore - 570 020, India \\ Tel: 918212516502 \\ Fax: 918212517233 \\ E-mail: blakshmi_1999@yahoo.com \\ Vinod Kumar \\ Plant Cell Biotechnology Department \\ Central Food Technological Research Institute \\ Mysore - 570 020, India \\ Tel: 918212516502 \\ Fax: 918212517233 \\ E-mail: vinu9628@yahoo.com \\ Venkatachalam Lakshmanan \\ Plant Cell Biotechnology Department \\ Central Food Technological Research Institute \\ Mysore - 570 020, India \\ Tel: 918212516502 \\ Fax: 918212517233 \\ E-mail: genevenki@yahoo.com
}

\section{Sreedhar Reddampalli Venkataramareddy \\ Plant Cell Biotechnology Department \\ Central Food Technological Research Institute \\ Mysore - 570 020, India \\ Tel: 918212516502 \\ Fax: 918212517233 \\ E-mail: rvsree@rediffmail.com}

\author{
Ravishankar Gokare Aswathanarayana \\ Plant Cell Biotechnology Department \\ Central Food Technological Research Institute \\ Mysore - 570 020, India \\ Tel: 918212516502 \\ Fax: 918212517233 \\ E-mail: pcbt@cscftri.ren.nic.in
}

Financial support: Senior and Junior Research Fellowship from the Council of Scientific and Industrial Research, India.

Keywords: Agrobacterium rhizogenes, auxins, elicitation, T-DNA, thermostability, transformation.

Abbreviations: IAA: Indole acetic acid;

NAA: Naphthalene acetic acid.

The genetically transformed roots of red beet have been shown, for the first time, to produce very high levels of peroxidase (POD; EC 1.11.1.7) accounting for $1.21 \times 10^{6}$ Units $L^{-1}$. Of the ten clones established using different strains of Agrobacterium rhizogenes, one was that from the strain LMG-150, three each from A 2/83, A 20/83 and A4. All the clones showed true integration of $\mathrm{T}$ DNA when tested by PCR and Southern hybridization

* Corresponding author 
methods. Each clone differed significantly from the others in growth, hormone dependency and POD production where LMG-150 produced highest biomass $\left(140 \mathrm{~g} \mathrm{FW} \mathrm{L}^{-1}\right.$ ) as well as POD (ranging from 8000-9000 $\mathrm{U} \mathrm{g}^{-1} \mathrm{FW}$ and $1.18 \times 10^{6} \mathrm{U} \mathrm{L}^{-1}$ with a specific activity of $600 \mathrm{U} \mathrm{mg}^{-1}$ protein) on hormone-free medium, both in shake-flask as well as in bioreactor with a further enhancement to $1.21 \times 10^{6} \mathrm{U} \mathrm{L}^{-1}$ upon the addition of extra calcium chloride $(5 \mathrm{mM})$. PAGE with active staining showed 4 distinct bands of $R_{m} 0.06,0.16,0.25$, 0.38 and 0.46 in the biomass and bands at $R_{m} 0.06,0.16$, 0.25 and one extra band of $R_{m} 0.575$ in the spent medium where isozymes of $R_{m} 0.38$ and 0.46 were totally absent. The pH optima and other properties were grossly comparable with the standard horse-radish POD (HRP) with better thermal stability than HRP and therefore, the present source appears to offer a cheaper and additional alternative for the commercial production of POD.

Plants remain as indispensable source for a number of chemical substances that are difficult to synthesize chemically owing to their complicated structures. For various reasons, the cultured cells and organs of higher plants are preferred over the conventional source for a wide array of proteins, secondary metabolites and biologically active substances. However, the unstable productivities often encountered in callus and cell suspension cultures indicate the alternative types of cultures, the organ cultures. Hairy roots, obtained after genetic transformation of host cell by Agrobacterium rhizogenes, are genetically stable and express faster growth rate than the normal roots (Doran, 2002). Above all, such roots are amenable for scale-up in large bioreactors and hence offer better advantages compared to cell cultures, and therefore, are widely preferred for the production of various chemical substances that are akin to root systems.

Table 1. Peroxidase activity $\left(\mathrm{U} \mathrm{g}^{-1} \mathrm{FW}\right)$ in different parts of 20day-old red beet seedling and mature tuber at $\mathrm{pH}$ 6.0.

\begin{tabular}{|c|c|}
\hline Plant part & $\begin{array}{c}\text { Total POD activity } \\
\mathbf{U ~ g}^{-1} \mathbf{F W}\end{array}$ \\
\hline 20 day old seedling & \\
\hline Leaf blade & 3591.5 \\
\hline Petiole & 2623.4 \\
\hline Root & 9700.3 \\
\hline Mature tuber & \\
\hline Peel & 6116.0 \\
\hline Pulp & 1492.5 \\
\hline Pulp + Peel & 4398.0 \\
\hline
\end{tabular}

Peroxidase (E.C.1.11.1.7) (POD) is an enzyme known to play a very crucial role in scavenging free radicals (peroxides) within the plant system (Regalado et al. 2004) in addition to their involvement in various metabolic activities. Outside the plant system this enzyme has several commercial applications, the major ones being its use as an important component in chemical diagnostics and laboratory experiments (Regalado et al. 2004). Because of broader catalytic activity, a wide range of chemicals can be modified using POD and hence has varied applications in waste water treatment to remove phenolics, synthesis of various aromatic compounds and removal of peroxides from foodstuffs, beverages and industrial wastes (Torres et al. 1997; Ayala et al. 2000). An extensive array of use though can be found for this enzyme, a major bottleneck lies in its current high cost of production. Presently, horseradish has been the source of high quality POD for biochemical / clinical applications whereas certain agricultural wastes / by products have been suggested for the production of commercial-grade POD. However, these sources of POD are limited by difficulties in purification (Uozumi et al. 1992; Srinivas et al. 1999). A few plant cell/suspension cultures have been reported to produce considerable levels of POD (Veitch, 2004). For example, cell cultures of horseradish, radish, suspension cultures of carrot, peanut, tobacco, spinach, Vaccinium sp and cowpea (Melo et al. 1995; Veitch, 2004) produced appreciable levels of POD enzyme. However, these systems were of limited applications due to the slow growth rate of cell cultures, inconsistent product yield and genetic instability.

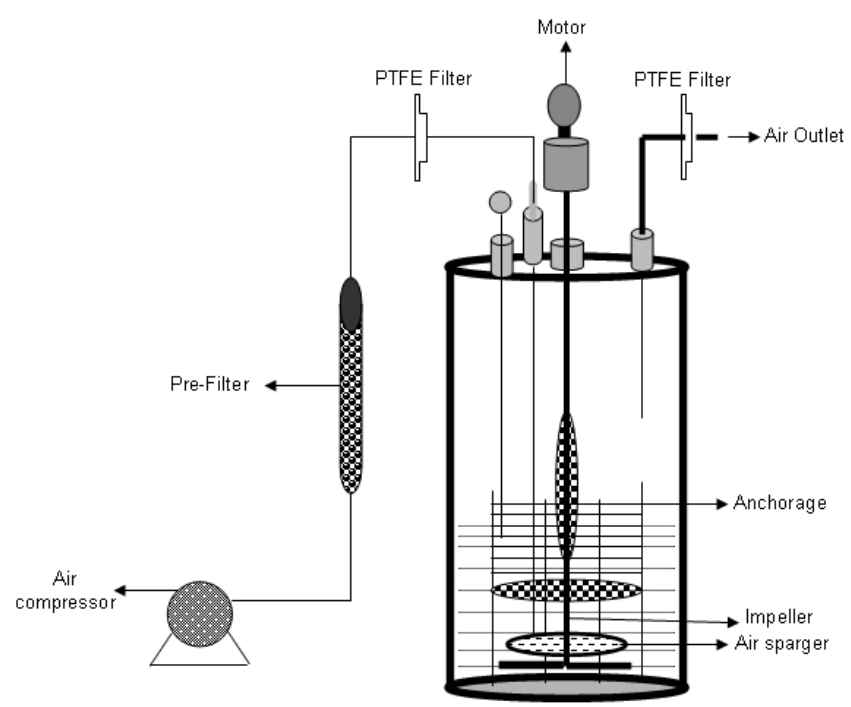

Figure 1. Diagrammatic representation of the bioreactor model used for the growth of hairy root clone LMG-150. The reactor was of $3 \mathrm{~L}$ capacity with a working volume of $1.75 \mathrm{~L}$. About $10 \mathrm{~g}$ of actively growing hairy roots were inoculated in to the anchorage basket held in growth vessel having MS basal liquid medium with $3 \%$ sucrose. The air was supplied at a rate of $33.4 \mathrm{~cm}^{3} \mathrm{~s}^{-1}$ through the glass sparger of $45 \mathrm{~cm}$ height and $7 \mathrm{~cm}$ diameter. The reactor was operated in dark at $23 \pm 2^{\circ} \mathrm{C}$ and after the required running period the reactor was dismantled and the biomass and spent medium were analyzed for POD. 
Hairy root cultures of carrot produced higher levels of POD of about $19.2 \mathrm{U} \mathrm{g}^{-1} \mathrm{FW}$ than the suspension cultures, which were correlated to increased phenolics content in the medium (Uozumi et al. 1992). Horseradish hairy root cultures have also been reported to produce considerably higher level of PODs (Uozumi et al. 1992; Flocco et al. 1998). Enhanced production of secondary metabolites and their related precursors were achieved by using different strategies such as selection of clone, changing growth conditions, particularly with reference to hormones and nutrients. Another interesting strategy is the exposure of cultures to changed environment such as treatment with elicitors. For example, treatment with different abiotic elicitors such as $\mathrm{AgNO}_{3}$ and $\mathrm{CuSO}_{4}$ caused about $100 \%$ increase in POD production in transformed root cultures of horseradish. Further, the metal ions caused secretion leading to an overall productivity of about 12-fold higher POD enzyme (Flocco et al. 1998). The heterotrophic hairy roots of Ipomoea aquatica were also found to produce POD at levels $250 \mathrm{U} \mathrm{g}^{-1} \mathrm{FW}$. When such roots were made autotrophic, the POD activity within the tissue nearly doubled which the authors related to the requirement of POD for scavenging the high release of toxic oxidants, the peroxides (Kino-Oka et al. 2001).

Table 2. Activity of different peroxidase fraction in hairy root clone LMG-150 grown in bubble column reactor ( $\left.\mathrm{U} \mathrm{g}^{-1} \mathrm{FW}\right)$ and percent total activity in the spent medium.

\begin{tabular}{|c|c|c|}
\hline $\begin{array}{c}\text { Peroxidase } \\
\text { fraction }\end{array}$ & $\begin{array}{c}\text { Total units of POD } \\
\text { activity per } \mathbf{~}^{-1} \mathbf{~ F W}\end{array}$ & $\begin{array}{l}\text { \% of the total activity } \\
\text { found in the medium }\end{array}$ \\
\hline Acidic (pH 4.0) & 13.8 & 13.4 \\
\hline pH 6.0 & 9932.0 & 5.9 \\
\hline Neutral (pH 7.0) & 3495.1 & 0.4 \\
\hline Basic (pH 9.0) & 4754.3 & 4.9 \\
\hline
\end{tabular}

Since the hairy root clone obtained by each transformed plant cell is expected to be genetically different conferred due to the difference with respect to the place of T-DNA integration (into the host genome) and the number of TDNA copies that get integrated into the genome (Doran, 2002), each clone is expected to behave differently with respect to growth and metabolite production. Therefore selection of a hairy root clone having properties of high biomass accumulation and POD production forms one of the important and unexploited strategies to obtain a stable and high level of enzyme production. Hairy root cultures of red beet have been studied extensively for the production of natural food colorants, the betalaines (Thimmaraju et al. 2003a; Thimmaraju et al. 2003b; Suresh et al. 2004; Thimmaraju et al. 2004). This communication reports, for the first time, that they can also be used for the production of high levels of POD enzymes. Therefore, the aim of the present study was to establish different clones of red beet hairy root cultures using different $A$. rhizogenes strains, study their growth pattern and the levels of POD production to select the most suitable hairy root clone for scale up in a bioreactor. The present study also considers other aspects that might influence the enzyme productivities such as the effect of different metal ions on the production and secretion of POD into the medium so that the same is amenable for in situ recovery (Uozumi et al. 1992; Thimmaraju et al. 2004).

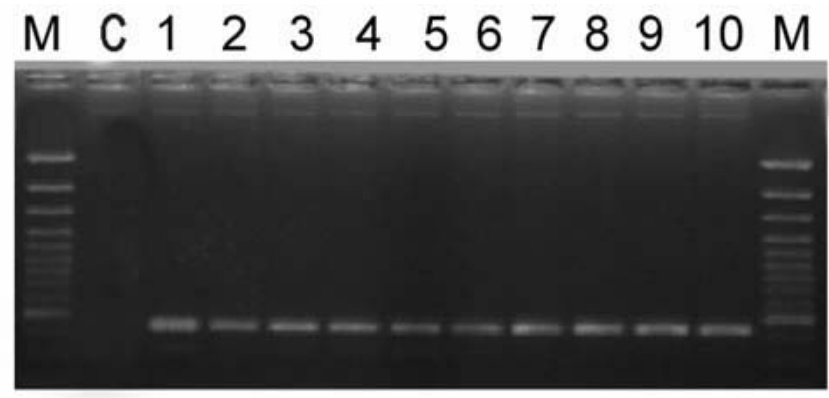

Figure 2a

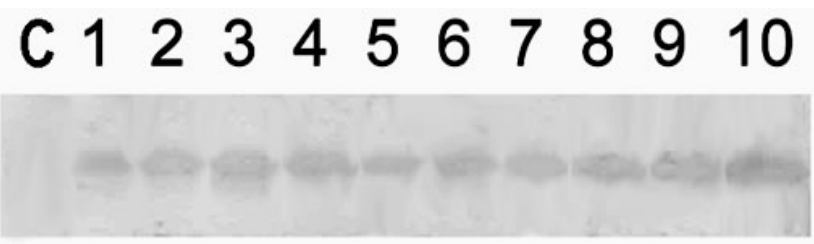

Figure 2b

Figure 2. Confirmation of transgenic nature of hairy root clones by PCR (a) and Southern analysis (b). Lanes 1-10; LMG-150; A4 (1); A4 (2); A4 (3); A 2/83(1); A 2/83(2); A 2/83(3); A 20/83(1); A 20/83(2); $A$ 20/83(3); $M=$ Marker i.e., 100 bp ladder; $C=$ untransformed control from seedling explants. PCR was performed using rolA gene specific primer sets (forward- 5' AGA ATG GAA TTA GCC GGA CTA 3' and reverse- 5' GTA TTA ATC CCG TAG GTT TGT TT -3') (Sigma, USA), which were designed using Primer3 software. The amplified DNA was run on $0.8 \%(\mathrm{w} / \mathrm{v})$ agarose gel to separate the DNA fragments, transferred to nylon membrane (BioBond $^{\mathrm{TM}}$-Plus, Sigma). Southern analysis (b) was done by probing with a psoralen biotin (Ambion Inc, USA) labelled 308 bp fragment of the rolA gene.

\section{MATERIALS AND METHODS}

\section{Establishment of hairy roots}

Red beet seeds of variety "Ruby Queen” were obtained from Indo-American Hybrid Seeds, Bangalore, India. The seeds were surface disinfected and sown aseptically on MS medium with $2 \%$ sucrose and three week old seedlings were used as the source of cotyledonary leaves from which the hairy roots were induced. The superiority of cotyledonary leaves for hairy root induction had been established earlier by screening different seedling parts. The cotyledonary leaf explants were aseptically infected, by following standard protocols, with different strains of $A$.LMG-150, A 2/83, A4, A 20/83 (Doran, 2002; Thimmaraju et al. 2003a). The A. rhizogenes clones were known to induce hairy roots in several other plant systems. The hairy 
root clone arising independently from each transformed cell was made bacteria-free using cefotaxime $\left(200 \mathrm{mg} \mathrm{L}^{-1}\right)$ and the bacteria-free clones were maintained in $50 \mathrm{ml}$ conical flask containing $15 \mathrm{ml}$ of Murashige and Skoog's (Murashige and Skoog, 1962) liquid medium with $30 \mathrm{~g}$ sucrose (MS). Root tips were subcultured every three weeks into fresh medium and the cultures were maintained on a gyratory shaker at $90 \mathrm{rpm}$ in dark at $25 \pm 2^{\circ} \mathrm{C}$, unless otherwise mentioned.

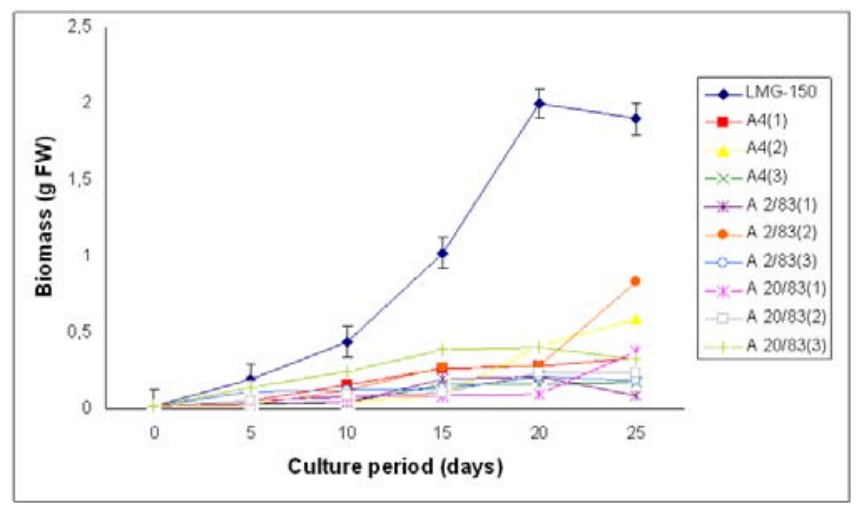

Figure 3. Pattern of growth and biomass accumulation in different clones of hairy roots over a 25-day growth period. About $50 \mathrm{mg}$ of root tips each of the 10 hairy root clones were subcultured in $50 \mathrm{ml}$ Erlenmeyer's flasks containing $15 \mathrm{ml}$ of MS basal liquid medium with $3 \%$ sucrose and grown on a rotary shaker set at $90 \mathrm{rpm}$ in dark at $23 \pm 2^{\circ} \mathrm{C}$. The biomass accumulation was monitored at an interval of 5 days for a total period of 25 days. Fresh weight increase was recorded after surface drying the roots by keeping between folds of blotter sheets. The data is the average of 5 replicates of two independent experiments each and the bars indicate SE of mean.

Agrobacterium rhizogenes is a soil bacterium known to lodge DNA plasmids having T-DNA region that gets transferred to higher plant genome. The T-DNA has several genes, of which the important ones are the rol genes (rol A, $\mathrm{B}, \mathrm{C}, \mathrm{D})$, aux genes involved in auxin metabolism and opine synthesizing genes. Since auxin is also synthesized by the higher plants, the other genes such as rol genes and opine synthesis character of hairy roots are generally tested to confirm the integration of T-DNA into the host genome (Doran, 2002). In the present study, we have chosen to test the presence of one of the rol genes, i.e., rolA for the confirmation of the integration of T-DNA from the plasmids of $A$. rhizogenes which was done by following polymerase chain (PCR) reaction. For PCR analysis (Hamill and Lidgett, 1997), a known quantity of bacteriafree roots grown in MS basal medium were removed, blotted gently on sterile filter paper and quickly frozen in liquid nitrogen. Thereafter, genomic DNA from putative transformants and normal roots (untransformed) was extracted by using the plant genomic DNA preparation kit GenElute $^{\mathrm{TM}}$ supplied by Sigma, USA as per the manufacturer's instruction. The rol genes have been fully characterized by earlier workers and their nucleic acid sequences are available in the bioinformatics database
(NCBI GeneBank). PCR was performed using rolA gene specific primer sets (forward- 5' AGA ATG GAA TTA GCC GGA CTA 3' and reverse- 5' GTA TTA ATC CCG TAG GTT TGT TT -3') (Sigma, USA), which were designed using Primer3 software for the rolA gene sequence from accession No. AB006688 from NCBI GeneBank. The PCR mixture $(25 \mu \mathrm{l})$ contained $50 \mathrm{ng}$ of DNA prepared from normal and hairy roots respectively as the template, 1X PCR buffer, 25 pmoles of each primer, 2.5 $\mathrm{mM}$ of dNTPs and 1 unit of Taq DNA polymerase (MBI fermentas). PCR was carried out by amplifying with initial denaturation at $94^{\circ} \mathrm{C}$ for 5 min followed by 35 cycles each of 1 min denaturation at $94^{\circ} \mathrm{C}, 1 \mathrm{~min}$ annealing at $55^{\circ} \mathrm{C}$ and $1 \mathrm{~min}$ extension at $72^{\circ} \mathrm{C}$ with a final extension of $72^{\circ} \mathrm{C}$ for 10 min using Eppendorf (Model: 22331) thermal cycler. The amplified DNA was run on $0.8 \%(\mathrm{w} / \mathrm{v})$ agarose gel to separate the DNA fragments, transferred to nylon membrane (BioBond $^{\mathrm{TM}}$-Plus, Sigma) using standard protocols of Southern analysis (Hamill and Lidgett, 1997) and probed using psoralen biotin (Ambion Inc, USA) labelled $308 \mathrm{bp}$ fragment of the rolA gene obtained from $A$. rhizogenes strain ATCC 15834 using the above said primers. The probe was prepared by using PCR amplified fragment of rolA gene after purification using Qiagen PCR purification kit (MinElute ${ }^{\mathrm{TM}}$ ) and labeled with psoralen biotin. The labeling, hybridization and detection were done with Ambion Bio detect kit (Ambion Inc, USA), according to the manufacturers instructions.

\section{Growth of hairy roots}

Once the clones were confirmed for their transformed nature, the clones were characterized for their growth performance, POD production and their response to auxins and abiotic elicitors. For testing growth performance, about $50 \mathrm{mg}$ of root tips of 10 hairy root clones were subcultured in $50 \mathrm{ml}$ Erelenmeyer's flasks containing $15 \mathrm{ml}$ of MS basal liquid medium with $3 \%$ sucrose and grown on a rotary shaker as described earlier. The biomass accumulation was monitored at an interval of 5 days for a total period of 25 days. Fresh weight increase was recorded after surface drying the roots by keeping between folds of blotter sheets.

\section{POD production}

The POD activity in each clone was monitored at an interval of 5 days for a total period of 30 days. Similarly, the non-transformed beetroot parts and seedling parts (grown both in vivo and in vitro) were also tested for the enzyme. For this, different POD fractions were extracted separately using separate buffers where the acidic POD was extracted by homogenizing $50 \mathrm{mg}$ fresh tissue of hairy roots, seedling parts and mature beetroot (tuber) parts in 1 $\mathrm{ml}$ of sodium acetate buffer $(\mathrm{pH} 4)$ containing $1 \mathrm{mM}$ DTT, $0.1 \mathrm{mM}$ PMSF. Similarly the other PODs such as of $\mathrm{pH}$ 6.0 , neutral and basic fractions were extracted using sodium 
phosphate buffer of $\mathrm{pH}$ 6.0, sodium phosphate buffer of $\mathrm{pH}$ 7.0 and Tris-buffer of $\mathrm{pH} 9.0$ respectively, each containing $1 \mathrm{mM}$ DTT and $0.1 \mathrm{mM}$ PMSF. After homogenization the homogenate was centrifuged at $12,000 \mathrm{rpm}$ twice and the supernatant was assayed for POD activity (Wititsuwannakul et al. 1997). Briefly, $1 \mathrm{ml}$ assay mixture was prepared which consisted $100 \mu \mathrm{l}$ of $1 \% \mathrm{H}_{2} \mathrm{O}_{2}, 100 \mu \mathrm{l}$ of $0.25 \%$ ortho-di-anisidine hydrochloride, $10 \mu \mathrm{l}$ of enzyme extract and $790 \mu \mathrm{l}$ of respective buffer. The change in OD per minute $\left(\mathrm{dA} \mathrm{min}^{-1}\right)$ was recorded using kinetic program in UV- visible spectrophotometer (Shimadzu UV-160A) at $460 \mathrm{~nm}$. The results were expressed as units per gram fresh weight $\left(\mathrm{U} \mathrm{g}^{-1} \mathrm{FW}\right)$, using standard horseradish POD enzyme obtained from ICN-biochemicals, where one unit refers to change of absorbance of 1 OD per minute. To quantify the extra cellular POD in the medium, the spent medium was taken and centrifuged twice at $12,000 \mathrm{rpm}$ at $4^{\circ} \mathrm{C}$ to remove cell debris if any and the supernatant was assayed for enzyme activity. The total protein concentration was determined by following the Lowry's method.

\section{Influence of auxins}

Ten mg each of different hairy root clones were inoculated into $50 \mathrm{ml}$ conical flasks containing $15 \mathrm{ml}$ of MS liquid medium with 0.5 and $1.0 \mathrm{mg} \mathrm{L}^{-1}$ of either Indole acetic acid (IAA) or Naphthalene acetic acid (NAA) and incubated on an orbital shaker kept at $90 \mathrm{rpm}$ maintained at $25^{\circ} \mathrm{C}$. The total biomass (fresh weight in $\mathrm{g} \mathrm{L}^{-1}$ ) and POD activity were analyzed at the end, i.e., on $20^{\text {th }}$ day and POD productivity level was expressed as units of enzyme produced per litre of medium.

\section{Influence of salts}

For horseradish hairy roots the additional ionsupplementation considerably enhanced the release of POD into the medium (Uozumi et al. 1992). Therefore, to check for similar influence in the present system the cultures were exposed to MS liquid medium containing additional levels of different ions in salt forms such as $\mathrm{NaCl}, \mathrm{KCl}, \mathrm{MgCl}_{2}$, $\mathrm{CaCl}_{2}, \mathrm{Na}_{2} \mathrm{SO}_{4}, \mathrm{Na}_{2} \mathrm{CO}_{3}, \mathrm{KNO}_{3}, \mathrm{FeCl}_{3}$ and EDTA at various concentrations such as 5, 10 and $15 \mathrm{mM}$. Hairy roots were cultured in $50 \mathrm{ml}$ Erlenmeyer's flask containing $15 \mathrm{ml}$ of MS medium incorporated with different ionic salts keeping rest of the conditions as mentioned earlier. Biomass and POD levels were estimated at the end of $20^{\text {th }}$ day and the POD productivity (activity $\mathrm{U} \mathrm{L}^{-1}$ ) and the POD released into the medium (also measured in terms of activity) were calculated.

\section{Intracellular and extra-cellular POD}

To further characterize the enzyme, the POD zymogram was prepared by polyacrylamide gel electrophoresis (7.2\%) (PAGE) carried out at $120 \mathrm{~V}$ for 4 hrs using $12 \times 14 \times 0.3$ cm gel without SDS using standard protocol. The gel was stained for POD activity with a $100 \mathrm{ml}$ solution of sodium phosphate buffer containing $10 \mathrm{ml}$ of $0.25 \%$ ortho-dianisidine hydrochloride and $10 \mathrm{ml}$ of $1 \%$ hydrogen peroxide (Wititsuwannakul et al. 1997) and immediately photographed.
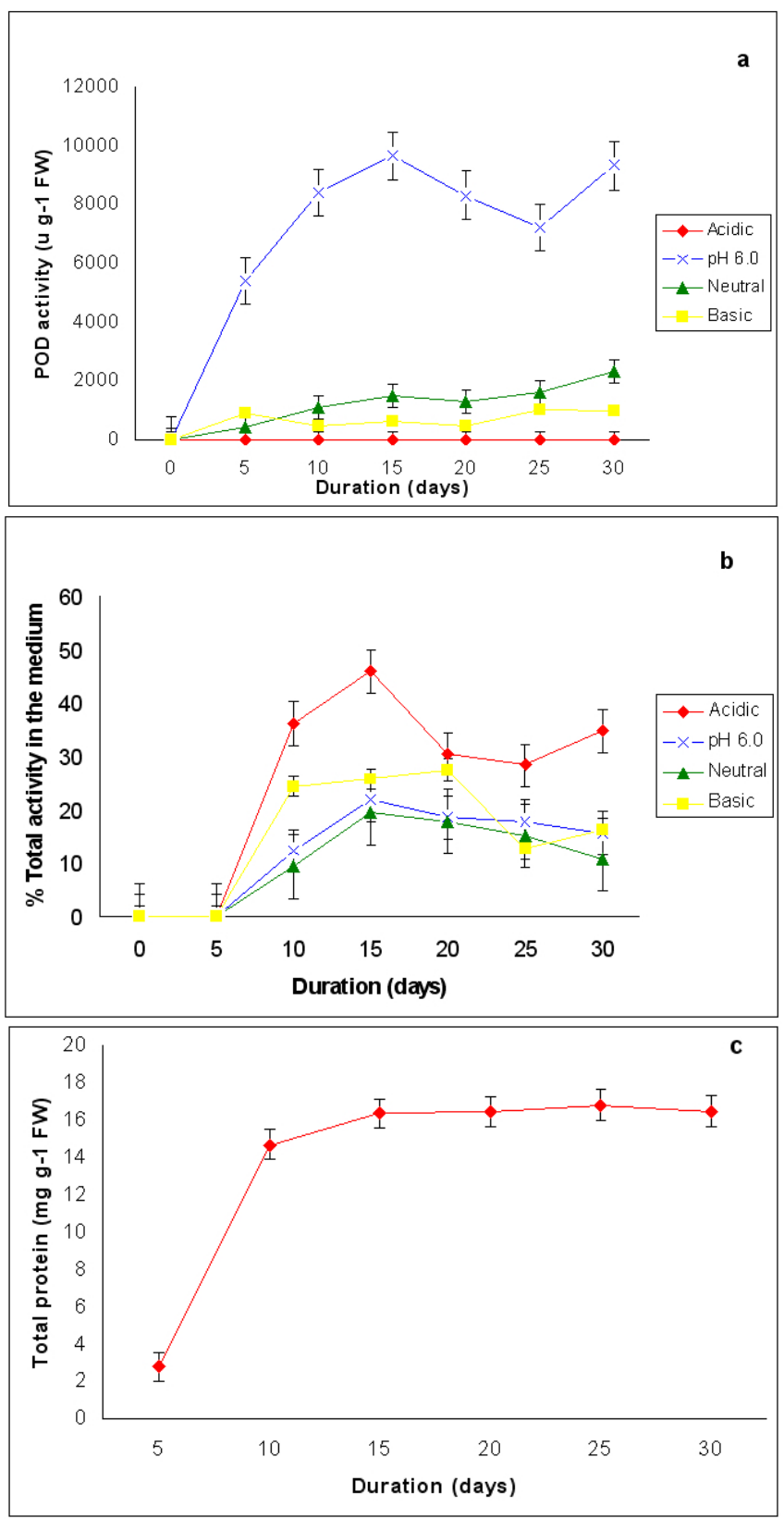

Figure 4. Totalactivities of different peroxidases (a), and the pattern of release of different peroxidases into the medium (b) and total protein content ( $\mathrm{mg} \mathrm{g}^{-1} \mathrm{FW}$ ) (c) in the clone LMG-150 cultured for 30 days. POD activity was monitored at an interval of 5 days for a total period of 30 days. Different POD fractions were extracted separately using separate buffers and the supernatant was taken from both medium and the extract from biomass for POD and total protein analysis. The data is the average of 5 replicates of two separate experiments. The bar indicates SE of mean. 


\section{Thermal stability of POD}

Thermal stability of the enzyme was determined by measuring the residual activity after incubating $100 \mu \mathrm{l}$ of the crude enzyme extract (the extraction of which has been explained earlier) at different temperatures in a shaking water bath. Aliquots $(10 \mu \mathrm{l})$ taken at different time intervals were assayed immediately and residual activity was expressed as per cent increase or decrease of activity.

\section{Production of POD in bioreactor}

Hairy root cultures were grown in a $3 \mathrm{~L}$ bubble column reactor (Suresh et al. 2004; Figure 1) with a working medium volume of $1.75 \mathrm{~L}$. Hairy root inoculum was prepared by sub culturing about $100 \mathrm{mg}$ of hairy roots of clone LMG-150 in $40 \mathrm{ml}$ medium in conical flasks for 10 days under standard conditions mentioned earlier. Totally $10 \mathrm{~g}$ fresh weight of actively growing hairy root inoculum was transferred aseptically through inoculation port into the anchorage basket of the growth chamber. The bioreactor was maintained in dark at $23 \pm 2^{\circ} \mathrm{C}$ with air supply through a sparger at a rate of $33.4 \mathrm{~cm}^{3} \mathrm{~s}^{-1}$. After the running period of 10 days, the biomass and the spent medium were analysed for the units of POD produced.

\section{Statistical analysis}

All treatments involved at least 5 replicates and the enzyme and PCR analyses had two replicates. All the experiments were repeated at least once and the data presented is the mean of two individual experiments and standard error of means (SE) were calculated applicable.

\section{RESULTS}

\section{Establishment of hairy root clones}

When cotyledonary leaf explants of red beet were cocultivated with different $A$. rhizogenes strains such as LMG -150, A 2/83, A 20/83 and A4 hairy roots started appearing from the cut surfaces of the explants 15 days after infection, possibly as a result of transformation. Though a large number of hairy root clones were produced from each set of explants, it was possible to free only ten clones from the perpetual occurrence of $A$. rhizogenes along with the hairy roots. Of the ten clones, one was that from the strain LMG150, three each from A 2/83, A 20/83 and A4. Each hairy root clone so obtained was named as LMG-150, A 2/83(1), A 2/83(2), A 2/83(3), A 20/83(1), A 20/83(2), A 20/83(3), A4(1), A4(2), A4(3).

Genomic DNA of all the clones when analysed for transformation first by PCR amplification using rolA specific primer, all the ten clones showed positive signals for both PCR and Southern hybridization (Figure 2A and
B) indicating the true integration of Ri T-DNA into host cell genome. Whereas normal beetroot (lane no. C) did not show any positive signal for rolA.

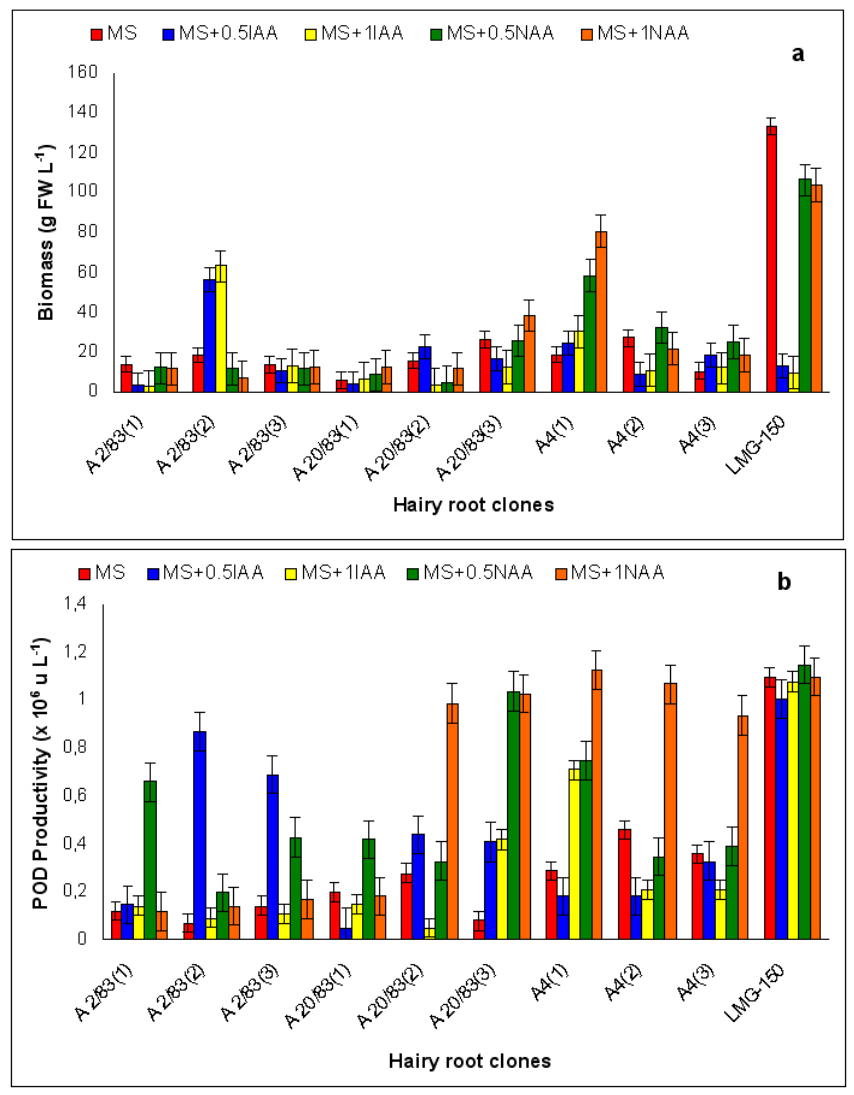

Figure 5. Growth (a) and peroxidase activity (b) in different hairy root clones grown in hormone free MS liquid medium and in MS with either IAA or NAA at either $0.1 \mathrm{mg} \mathrm{L}^{-1}$ or $1.0 \mathrm{mg} \mathrm{L}^{-1}$ observed on $20^{\text {th }}$ day of culture period. The data is the average of 5 replicates of two independent experiments and the bars indicate SE of mean values.

\section{Growth of hairy root clones}

Initially different clones were studied for their growth in terms of biomass production for a period of 25 days at 5 days intervals. As shown in Figure 3, of the 10 clones of transformed roots, the clone LMG-150 was the best clone in terms of biomass production in hormone-free MS liquid medium producing about $2.0 \mathrm{~g}$ fresh weight in $15 \mathrm{ml}$ MS liquid medium on $20^{\text {th }}$ day after inoculation, with a declining trend later. A2/83(2) was the next best clone in terms of growth and rest of the clones produced less than $0.5 \mathrm{~g}$ fresh weight (Figure 3). The clone LMG-150 showed a typical sigmoid growth curve accounting for much higher biomass compared to other clones.

\section{POD production}

In LMG-150 root clone, the activity of POD extracted at $\mathrm{pH} 6.0$ was highest on $15^{\text {th }}$ day producing about $9000 \mathrm{U} \mathrm{g}^{-1}$ 
FW followed by $8000 \mathrm{U} \mathrm{g}^{-1} \mathrm{FW}$ on $20^{\text {th }}$ day, and of the total about $30 \%$ of the POD in each case was secreted into the medium (Figure 4a and b). However, the enzyme extracted each at acidic ( $\mathrm{pH} 4.0)$, basic ( $\mathrm{pH}$ 9.0) and neutral ( $\mathrm{pH}$ 7.0) showed significantly lesser POD activity. In the medium on $15^{\text {th }}$ day, about $45 \%$ of the total activity was that of acidic and nearly $20 \%$ were those from $\mathrm{pH} 6.0$ and neutral. However, the basic POD was released at high levels accounting for $28 \%$ of the total found in the medium (Figure $4 \mathrm{~b}$ ). The total protein was highest on $15^{\text {th }}$ day and remained consistently as $15 \mathrm{mg} \mathrm{g}^{-1} \mathrm{FW}$ biomass (Figure 4c). The clone A 20/83(2) expressed higher level of POD i.e., nearly $12000 \mathrm{U} \mathrm{g}^{-1} \mathrm{FW}$ on $20^{\text {th }}$ day in MS liquid medium (data not shown). Since, the biomass was lower in this clone than LMG-150 accounting for lower productivity per litre, latter the clone LMG-150 was considered for detailed study. All the other clones produced either less or negligible total POD activity compared to the clone LMG150 (data not shown).
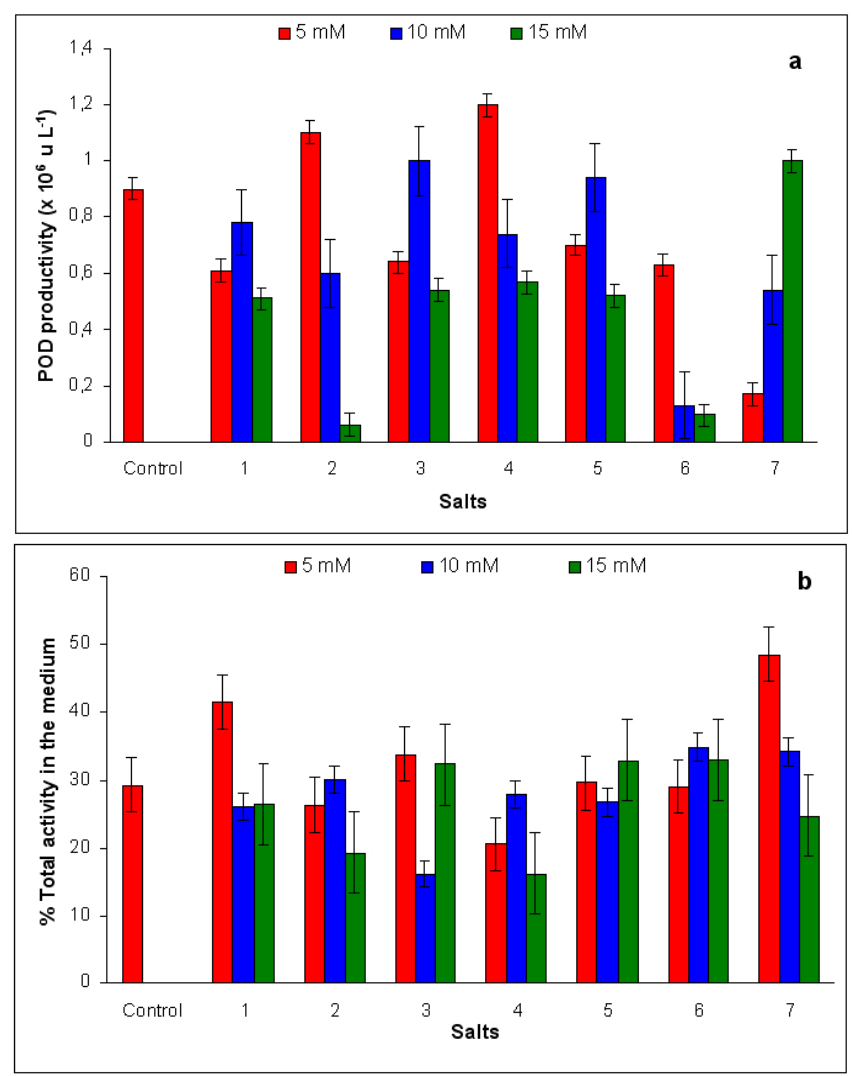

Figure 6. Effect of different salts at various concentrations on the level of activity (a) and secretion (b) of peroxidase enzyme in hairy root clone LMG-150 estimated on $20^{\text {th }}$ day of the culture period (Xaxis: 1: $\mathrm{NaCl}, 2: \mathrm{KCl}, 3: \mathrm{MgCl}_{2}, 4: \mathrm{CaCl}_{2}, 5: \mathrm{Na}_{2} \mathrm{SO}_{4}, 6: \mathrm{Na}_{2} \mathrm{CO}_{3}, 7:$ $\mathrm{KNO}_{3}$ ).

To check whether the high level of POD activity observed in hairy roots was due to transformed nature of root or not, the non-transformed tissues were also screened for POD activity. Table 1 shows that among the seedling parts whether grown in vitro on MS medium or in the soil, the roots expressed almost similar activity of POD $\left(9000 \mathrm{U} \mathrm{g}^{-1}\right.$ FW) whereas the cotyledonary leaf that was used for inducing hairy roots in the present study showed much lesser level of about $3591 \mathrm{U} \mathrm{g}^{-1} \mathrm{FW}$ of POD activity. In the mature red beet tuber (grown in the field), peel showed maximum activity of $6116 \mathrm{U} \mathrm{g}^{-1} \mathrm{FW}$ which again was much lesser than that found in hairy roots (Table 1).

\section{Influence of auxin}

While the root clone LMG-150 showed high biomass productivity of $140 \mathrm{~g} \mathrm{FW} \mathrm{L}^{-1}$ on hormone-free medium, the other clones produced very low biomass. The clone LMG150 was unable to grow in the presence of any level of IAA whereas growth was fair in the presence of NAA though the latter also suppressed biomass when compared with control (Figure 5a). IAA significantly supported biomass formation in the second clone of A 2/83 whereas NAA supported better biomass than in control in the first clone of A4, followed by third clone of the same and the third clone of A20/83. In general, both the auxins IAA and NAA appeared to suppress the biomass accumulation in clone LMG-150, whereas for most of the other clones either IAA or NAA was beneficiary either marginally or significantly (Figure 5a).

Unlike the biomass, the productivity (units $\mathrm{L}^{-1}$ ) of POD $(\mathrm{pH}$ 6.0) in the best clone LMG- 150 was almost similar with or without auxin treatment accounting for about $1 \times 10^{6}$ units of POD activity per litre medium (Figure 5b). Similarly, in most of the other clones, the POD productivity was enhanced significantly by the auxins and in some of them the productivities were on par with that of the best clone. The clones A 20/83(2), A 20/83(3), A4(1), A4(2) and A4(3) performed better than their respective controls when supplemented with $1 \mathrm{ppm}$ of NAA producing about $1 \times 10^{6}$ units of POD activity per litre. Whereas the clones A 2/83(2) and A 2/83(3) produced higher POD in the presence of $0.5 \mathrm{ppm}$ IAA accounting for about $0.8 \times 10^{6}$ and $0.6 \times 10^{6} \mathrm{U} \mathrm{L}^{-1}$ respectively (Figure 5b).

\section{Influence of salts}

Among the different salts used in addition to those already present in the medium, $\mathrm{FeCl}_{3}$ as well as EDTA completely suppressed growth and POD activity levels even in the best clone LMG-150 (data not presented). Among the other metal ions used $\mathrm{CaCl}_{2}$ at $5 \mathrm{mM}$ concentration produced slightly higher POD activity of about $1.21 \times 10^{6} \mathrm{U} \mathrm{L}^{-1}$. Further higher concentrations appeared to suppress the enzyme productivities in a dose dependent manner. $\mathrm{KCl}$ produced slightly higher POD activity (Figure 6a) than the control accounting for about $1.11 \times 10^{6}$ units per litre with a suppression of activity at higher treatment levels. Most of the other ions either produced same amount of POD or 
appeared to suppress the enzyme at higher treatment levels, except for $\mathrm{KNO}_{3}$ where higher the level better was the POD activity (Figure 6b).

Maximum release of POD measured in terms of activity was observed in the presence of $5 \mathrm{mM} \mathrm{KNO}_{3}$ (nearly 50\%) that was followed by only $\mathrm{NaCl}$ (43\%) (Figure 6B), whereas treatments with other metal ions at three different concentrations did not cause any significant effect on POD secretion.

\section{Intracellular and extra-cellular POD}

Figure 7 shows the active staining of PODs of intra- and extra-cellular ones separated on $7.2 \%$ polyacrylamide gel. POD from the hairy roots of clone LMG 150 showed 5 distinct bands each corresponding to relative mobility $\left(\mathrm{R}_{\mathrm{m}}\right)$ of 0.06 (designated as F), 0.16 (E), 0.25 (D), 0.38 (C), 0.46 (B). Of these $\mathrm{D}, \mathrm{E}$ and $\mathrm{F}$ were found in the spent medium. The bands $\mathrm{B}$ and $\mathrm{C}$ were not present in the medium. Whereas the band with $R_{m}$ value of 0.575 (A) was found only in the medium, which was absent in the biomass and this may be the isozyme that was completely secreted in to the medium. Therefore, red beet hairy roots totally produced about 6 POD isoforms of which three were secreted partially into the medium and only one was completely secreted into the medium. The protein molecular markers on the extreme right lane of Figure 7 gives a rough idea about the nature of isozymes though a native gel should not be compared with such markers.

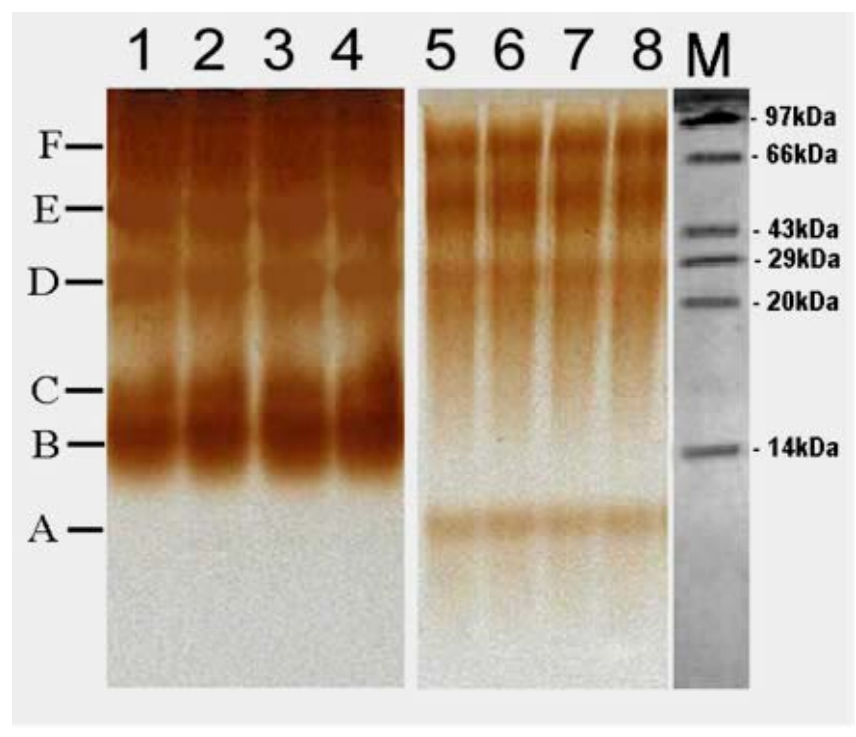

Figure 7. Zymogram of peroxidase isozymes from roots (Lanes 1 4) and from spent medium (lanes 5 - 8) developed by activity staining of the enzyme separated on $7.2 \%$ native polyacrylamide gel. The electrophoresis was carried out by loading about $20 \mu \mathrm{l}$ each of crude enzyme preparation from both biomass and spent medium in a $7.2 \%$ polyacrylamide gel $\left(12^{\prime} 14^{\prime} 0.3 \mathrm{~cm}\right)$ (PAGE) carried out at $120 \mathrm{~V}$ for $4 \mathrm{hrs}$. Similarly about $10 \mu \mathrm{l}$ of standard protein molecular weight marker mix was also loaded and stained with coomassie brilliant blue R-250 (lane M) separately after electrophoresis.

\section{Thermostability}

Figure 8 (a-d) shows the percent increase or decrease of POD activity as a function of three different temperatures during a total period of $60 \mathrm{~min}$. The thermal inactivation of PODs extracted at acidic and neutral $\mathrm{pH}$ was negligible upto $50^{\circ} \mathrm{C}$ with almost $95 \%$ of the activity being retained even after 40 min. However, the POD of basic $\mathrm{pH}$ was very sensitive to temperature with $50 \%$ loss at $50^{\circ} \mathrm{C}$ in $40 \mathrm{~min}$, with total loss of activity at $60^{\circ} \mathrm{C}$. At the latter temperature $\left(60^{\circ} \mathrm{C}\right)$ the acidic and neutral PODs retained more than $70 \%$ of the activity upto 40 min whereas these enzymes were completely inactivated at $70^{\circ} \mathrm{C}$.

\section{POD production in bioreactor}

The best clone LMG-150 was grown in a bubble column reactor for 10 days. As shown in Table 2, even here this clone produced almost same amount of total POD as observed in the shake flask, except that there was slight reduction in the quantity of extra cellular POD. A total POD of about $9000 \mathrm{U} \mathrm{g}^{-1} \mathrm{FW}$ was produced in the bubble column reactor (Table 2).

\section{DISCUSSION}

\section{Establishment of hairy root clones}

As reported earlier (Xu et al. 2004) the cotyledonary leaves showed the best response to Agrobacterium infection resulting in the induction of roots that exhibited typical phenotypic characteristics of "hairy roots" such as intense hairiness, plagiotrophic growth, higher lateral branching and faster growth than the normal roots. Above all, the roots were able to grow well on hormone-free medium indicating the harmone-independent nature of roots that generally results due to their transformed nature (Hamill and Lidgett, 1997). In most of the earlier studies, the transformation of plant tissues by $A$ rhizogenes was generally confirmed by using biochemical method, i.e., by the detection of opines in plant tissues. In the present study the hairy root clones were tested for transformation and integration of T-DNA into the red beet genome first by means of PCR amplification using rolA-gene-specificprimer and second by doing PCR - Southern hybridization using 301 bp long psorelen-biotin labeled rolA gene specific probe. Thus the presence of rolA specific band upon PCR amplification and Southern hybridization clearly established the proof for successful transformation (Figure 2a and $b$ ).

\section{Biomass accumulation and POD activity}

Among the ten hairy root clones established, there was a clear-cut difference from one clone to another in terms of biomass accumulation and the profile of POD activity 
(Figure 3; Figure 5b). These differences may be attributed to the secondary variation in the T-DNA insertion, copy number, size and location of integration of T-DNA of Ri plasmid into the plant genome (Doran, 2002) as also noted in horseradish hairy roots (Flocco et al. 1998). The best clone LMG-150 established in the present study produced POD of about $9000 \mathrm{U} \mathrm{g}^{-1} \mathrm{FW}$, which was significantly higher than the POD activity reported for horseradish hairy roots (Flocco et al. 1998). The kinetic studies showed that the POD activity was high during mid-exponential growth phase and declined further as the biomass reached its peak on $25^{\text {th }}$ day as also observed by Flocco et al. (1998). This is probably due to high metabolic activity during which the pro-oxidants are formed sending signals for the release of POD to quench the oxidant molecules, as has been suggested for Ipomoea aquatica (Kino-Oka et al. 2001). The low productivities of PODs of other $\mathrm{pH}$ may also be due to the same reason that most of the metabolic activities occur at $\mathrm{pH}$ ranging from 5.5 - 6.0, which is well known. Similarly in non-transformed seedling tissues and tubers it is the seedling root that expressed maximum POD activity (irrespective of in vivo or in vitro conditions of seedling growth) and not the tuber indicating that it is the rooty morphology probably playing a role in signaling POD expression. Thus the transformed nature of red beet hairy roots harbouring genes for root morphology i.e., rol genes (Lemcke and Schmulling, 1998; Thimmaraju and Bhagyalakshmi, 2005) is probably one reason for the overexpression of POD, as in seedling roots rather than in the mature tubers. The higher expression of POD in the skin of red beer tuber may be attributed to defence related activities or due to elicitation by surface borne micro-organisms, since several soil-borne microbes are known to elicit phenyl propanoid pathway, enhancing the intermediary enzymes as well (Radman et al. 2003). In hairy root clones LMG-150, the total protein content reached maximum on $10^{\text {th }}$ day and remained constant till the end of growth phase though growth ceased after $20^{\text {th }}$ day indicating the probable stability of certain enzymes such as POD. Since red beet hairy roots are also used for the production of betalaines, the red pigments for food applications (Thimmaraju et al. 2003a; Thimmaraju et al. 2003b; Thimmaraju et al. 2004), the hairy root system studied presently offer an excellent source for the simultaneous production of both pigment and enzyme.

\section{Influence of auxins}

The fact that auxins are involved in growth and morphogenesis of various types, especially roots, is well established. The exogenous application of two auxins in the present study did not cause any significant improvement of biomass accumulation in most of the clones, except in clones A 2/83(2) and A4 (1) where there were significant improvements in biomass after the supplementation of auxins. Such hormone dependency for growth has also been
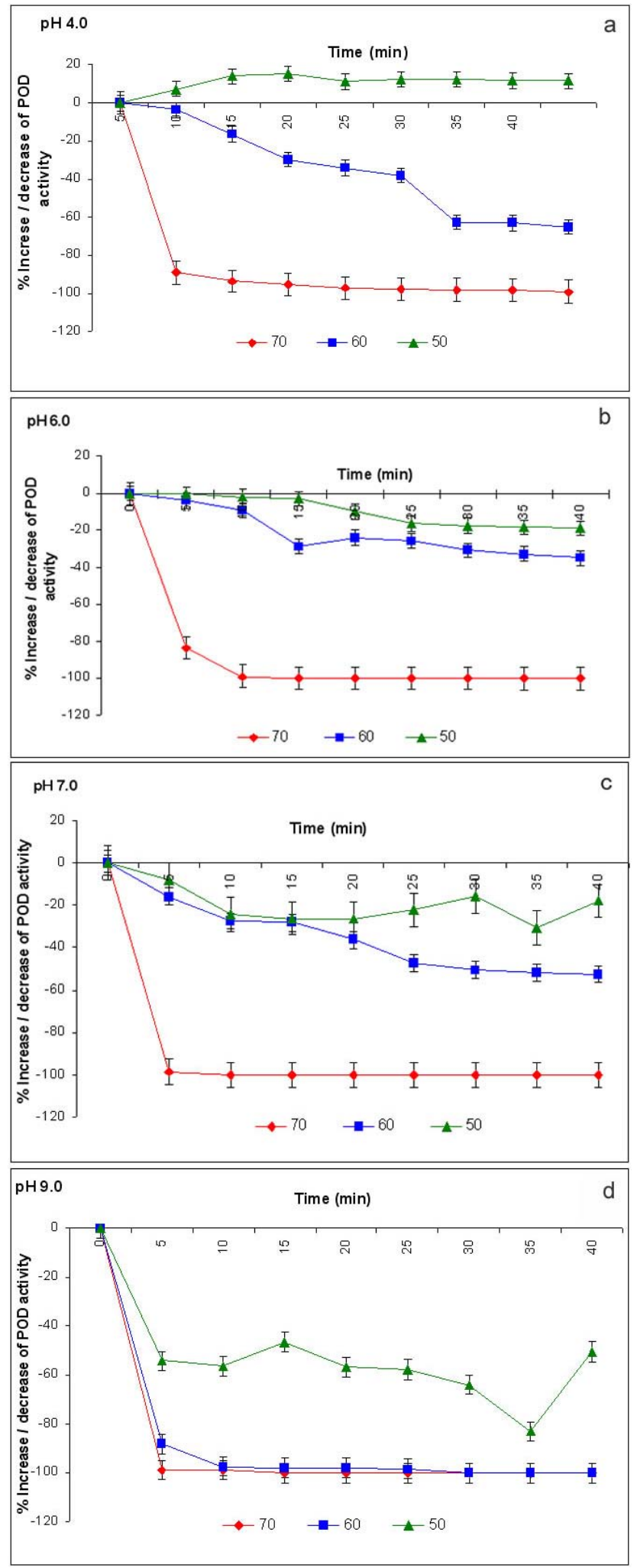

Figure 8. Thermostability of crude peroxidase enzyme fractions at three different temperatures $\left(50,60\right.$ and $\left.70^{\circ} \mathrm{C}\right)$ recorded for 40 min time period. About $500 \mu \mathrm{l}$ of the crude enzyme extract prepared at different $\mathrm{pH}$ was incubated at three different temperatures and the rate of loss of activity was monitored by taking $10 \mu \mathrm{l}$ from each of the treatments and measuring the activity i.e., dA $\min ^{-1}$ at $460 \mathrm{~nm}$. The data is the average of 5 replicates of two independent experiments. 
observed in hairy root cultures of Cichorium intybus (Bais et al. 2001) and horseradish hairy roots (Uozumi and Kabayashi, 1997). Contrarily, there was a very high variability when POD production was concerned. In many cases the POD activity increased in response to specific concentrations of auxins. Such responses may be attributed to the hormonal support or stress created on the hairy root clones apart from the well-known fact that POD has been implicated significantly in auxin metabolism (Liu et al. 1996). In cases where increased growth was observed, such as in clones A 2/83(2) and A4(1), the oxidants produced during various metabolic activities demand for the synthesis of this enzyme for scavenging $\mathrm{O}_{2}$ (pro-oxidants) and $\mathrm{H}_{2} \mathrm{O}_{2}$ (peroxides) (Kino-Oka et al. 2001). In addition, the POD being necessary for the cell during the stressrelated metabolism the presence of auxins may switch on the stress signal for the production of POD causing sudden increase of the same in most of the other clones where biomass is otherwise suppressed. Interestingly, the best clone LMG-150 did not respond significantly for auxin where POD levels remained almost constant even after treatment (Figure 5b) indicating that this clone neither utilizes exogenous auxin nor that the addition of hormones impart any stressed physiological conditions. The nonresponsiveness of this clone may be attributed to the lack of auxin-uptake metabolism from the cell exterior, particularly at levels that are tried in this study. However, it may be recalled that these levels were able to induce rooting and/or callus in untransformed cultures (Narayan et al. 2004). Since the different clones induced by the same strain of $A$. rhizogenes such as three clones each from A 2/83, A20/83 and A4 responded differently to different auxins, the present study clearly indicates that red beet hairy roots form an excellent model system to unravel the influence of $\mathrm{T}$ DNA on auxin metabolism.

\section{Influence of salts}

Data presented in Figure 6a show that the cations $\mathrm{Mg}^{2+}$, $\mathrm{Ca}^{2+}$ and $\mathrm{K}^{+}$from their respective salts caused slight increase in POD production while the other anions used such as $\mathrm{SO}_{4}{ }^{2-}, \mathrm{CO}_{3}{ }^{-}$and $\mathrm{Cl}^{-}$appeared to suppress the same. $\mathrm{NO}_{3}{ }^{-}$ions also suppressed POD activity at low concentrations, nevertheless producing the same at higher concentration. $\mathrm{Na}_{2}$-EDTA and $\mathrm{FeCl}_{3}$ completely suppressed the growth of the hairy roots, as has also been observed in other hairy root systems (Uozumi et al. 1992).

Among the different cations $\mathrm{Na}^{+}$and $\mathrm{Mg}^{2+}$ ions improved the secretion POD into the medium thus acting as effluxing agents. The involvement of these ions in membrane permeabilization acting as ion channels has been well established (Karpen and Ruiz, 2002). The other cations such as $\mathrm{K}^{+}$and $\mathrm{Ca}^{2+}$ did not cause any significant increase in POD secretion though these ions are also involved in the membrane activities and reported to cause secretion of POD in horseradish hairy roots (Uozumi et al. 1992). Supplementation of medium with anions such as $\mathrm{SO}_{4}{ }^{2-}$, $\mathrm{CO}_{3}{ }^{2-}$ and $\mathrm{NO}_{3}{ }^{-}$increased the extracellular POD activity with $\mathrm{NO}_{3}{ }^{-}$causing highest secretion of about $50 \%$ of the total POD (Figure 6b). This was in contrast to the earlier reports where $\mathrm{NO}_{3}{ }^{-}$had very little effect on secretion of POD (Uozumi et al. 1992). However, certain white rot fungi such as Phanerochaete flavido-alba has also been observed to respond positively to carbon limitation and excess of nitrogen leading to the leaching of lignin POD (Hamman et al. 1997).

\section{Isoperoxidase profile}

All the isoforms present in the hairy root biomass, except for two, were also found in the extra cellular medium but only one isoform of $R_{m} 0.575$ was found only in the medium but not in the biomass. This pattern indicates that four of the six isozymes were of secretary-type-proteins but the degree of secretion varied allowing a good scope for improving the secretion. The involvement of specific signals for leaching a specific type of POD isozyme forms an interesting study for the future. Further, there was a clear distinction between the different isoforms differing by $R_{m}$ value of at least 0.15 , which implies that the isoforms are amenable for easy separation and further purification (Figure 7).

\section{Thermostability}

The studies on thermal inactivation of crude POD from red beet clearly indicated that the enzyme is quite stable and only about $5 \%$ of reduction in the activity at $50^{\circ} \mathrm{C}$ even after 30 min (Figure 8). Thus the enzyme appears to be quite stable even above ambient temperature of $27-32^{\circ} \mathrm{C}$ promising a wide array of future applications.

\section{POD in bioreactor}

Though various metabolites are suppressed in a bioreactor when compared with the respective shake flask culture (Doran, 2002), the selected root clone of red beet i.e., LMG-150 performed well even in the bioreactor cultivation producing comparable levels of POD. Though there was a suppression of biomass in the bioreactor, leading to the lower overall productivity, such suppression was not very significant. Interestingly, the release of enzyme into the cell exterior was very limited in bioreactor, except for the one at acidic $\mathrm{pH}$ (Table 2). Contrarily there are other organized systems grown in bubble column bioreactor such as the somatic embryos of sandalwood, which released very high levels of PODs when grown in bioreactor (Pal et al. 2003). These observations indicate that the red beet hairy root system has several metabolic activities that need to be unraveled and hence appear as an interesting system for future studies. 


\section{CONCLUDING REMARKS}

The present study has clearly established that certain clones of red beet hairy roots produce copious levels of POD having good thermal stability. Since POD is also involved in lignin biosynthesis via phenyl propanoid pathway and the latter gets elicited to various biotic and abiotic elicitors, there is a high possibility for further enhancing the levels of POD by means of elicitation. The additional fact that the clone LMG -150 produced similar amounts of POD in a bubble column reactor as of shake flask cultures, indicate that the red beet hairy roots can be exploited for scaled up production of POD and the method appears to form a better alternative for horseradish POD. The observation that nearly half of the synthesized POD is secreted into the medium indicates the possibility of permeabilizing the roots for enhanced efflux of the enzyme even in bioreactor, as reported for the pigments from the same system (Thimmaraju et al. 2003a; Thimmaraju et al. 2003b; Suresh et al. 2004; Thimmaraju et al. 2004). Several other unit operations for scale-up of hairy root biomass have also been worked out and, therefore, the red beet hairy root system appears very promising for the production of this expensive enzyme.

\section{ACKNOWLEDGMENTS}

The authors thank Dr. V. Prakash, Director, CFTRI for his encouragement in the research activities.

\section{REFERENCES}

AYALA, Marcela; LOPEZ-MUNGUIA, Agustín; ROBLEDO, Norma R. and VAZQUEZ-DUHALT, Rafael. Substrate specificity and ionization potential in chloroperoxidase catalyzed oxidation of diesel fuel. Environmental Science and Technology, 2000, vol. 34, no. 13, p. 2804-2809.

BAIS, H.P.; GEORGE, J.; RAVISHANKAR, G.A. and SUDHA, G. Influence of exogenous hormones on growth and secondary metabolite production in hairy root cultures of Cichorium intybus L. cv. Lucknow local. In Vitro Cellular and Developmental Biology - Plant, March 2001, vol. 37, no. 2, p. 293-299.

DORAN, P.M. Properties and applications of hairy-root cultures. In: OKSMAN-CALDENTY, K.-M. and BARZ, W.H., eds. Plant biotechnology and transgenic plants. New York, Mercel Dekker Inc., 2002, p. 143-162.

ESCRIBANO, Josefa; GANDIA-HERRERO, Fernando; CABELLERO, Nuria and PEDREÑO, María Ángeles. Subcellular localization and isoenzyme pattern of peroxidase and polyphenol oxidase in beet root (Beta vulgaris L.). Journal of Agricultural and Food Chemistry, 2002, vol. 50, no. 21, p. 6123-6129.
FLOCCO, Cecilia Gabriela; ALVAREZ, María Alejandra and GUILIETTI, Ana María. Peroxidase production in vitro by Armoracia lapathifolia (horseradish)-transformed root cultures: Effect of elicitation on level and profile of isoenzymes. Biotechnology and Applied Biochemistry, 1998, vol. 28, p. 33-38.

HAMILL J.D. and LIDGETT J.A. Hairy root cultures Opportunities and key protocols for studies in metabolic engineering. In: DORAN, Pauline M. eds. Hairy roots culture and applications. Netherlands, Harwood Academic Publishers, 1997, p. 1-31.

HAMMAN, Ben O.; RUBIA, T. de la and MARTINEZ, J. Effect of carbon and nitrogen limitation on lignin peroxidase and manganese peroxidase production by Phenerochaete flavido-alba. Journal of Applied Microbiology, 1997, vol. 83, no. 6, p. 751-757.

KARPEN, Jeffrey W. and RUIZ, María Luísa. Ion Channels: does each subunit do something on its own?. Trends in Biochemical Sciences, 2002, vol. 27, no. 8, p. 402-409.

KINO-OKA, Masahiro; NAGATOME, Hirofumi and TAYA, Masahito. Characterization and application of plant hairy roots endowed with photosynthetic functions. Advances in Biochemical Engineering, 2001, vol. 72, p. 183-218.

LEMCKE, Kay and SCHMULLING, Thomas. A putative rolB gene homologue of the Agrobacterium rhizogenes TRDNA has different morphogenetic activity in tobacco than rolB. Plant Molecular Biology, 1998, vol. 36, p. 803-808.

LIU, Zin-Huang; LIU, Ho-Yih and WANG, Hwei-Yi. Effect of light on endogenous indole-3-acetic acid, peroxidase and indole-3-acetic-acid oxidase in soybean hypocotyls. Botanica Bulletin Academica Sinica, April 1996, vol. 37, no. 2, p. 113-119.

MELO, N.; CABRAL, J.M.S. and FEVEREIRO, P. Extracellular peroxidases from cell suspension cultures of Vaccinium myrtillus. Purification and characterization of two cationic enzymes. Plant Science, April 1995, vol. 106, no. 2, p. 177-184.

MURASHIGE, T. and SKOOG, F. A revised medium for rapid growth and bioassays with tobacco tissue culture. Physiologia Plantarum, 1962, vol. 15, p. 473-497.

NARAYAN, M.S.; THIMMARAJU, R. and BHAGYALAKSHMI, N.Interplay of growth regulators during solid-state and liquid-state batch cultivation of anthocyanin producing cell line of Daucus carota. Process Biochemistry, 2004, vol. 40, no. 1, p. 351-358.

PAL, Sanjay; DAS, Susobhan and DEY, Satyahari. 
Peroxidase and arabinogalactan protein as by-products during somatic embryo cultivation in air-lift bioreactor. Process Biochemistry, 2003, vol. 38, no. 10, p. 1471-1477.

RADMAN, Romeo; SAEZ, Teresa; BUCKE, Christopher and KESHAVARZ, Tajalli. Elicitation of plants and microbial cell systems. Biotechnology and Applied Biochemistry, 2003, vol. 37, p. 91-102.

REGALADO, Carlos; GARCIA-ALMENDAREZ, Blanca E. and DUARTE-VANQUEZ Miguel A. Biotechnological applications of peroxidases. Phytochemistry Reviews, January 2004, vol.3, no. 1-2, p. 243-256.

SRINIVAS, N.D.; RASHMI, K.R. and RAGHAVARAO, K.S.M.S. Extraction and purification of a plant peroxidase by aqueous two-phase extraction coupled with gel filtration. Process Biochemistry, October 1999, vol. 35, no. 1-2, 4348.

SURESH, B.; THIMMARAJU, R.; BHAGYALAKSHMI, N. and RAVISHANKAR, G.A. Polyamine and methyl jasmonate-influenced enhancement of betalaine production in hairy root cultures of Beta vulgaris grown in a bubble column reactor and studies on efflux of pigments. Process Biochemistry, 2004, vol. 39, no. 12, p. 2091-2096.

THIMMARAJU, Rudrappa and BHAGYALAKSHMI, Neelwarne. Rol genes of Agrobacterium rhizogenes and their biotechnological applications. Critical Reviews in Biotechnology. In press, 2005.

THIMMARAJU, Rudrappa; BHAGYALAKSHMI, Neelwarne and RAVISHANKAR, G.Aswathanarayana. In situ and ex situ adsorption and recovery of betalaines from hairy root cultures of Beta vulgaris. Biotechnology Progress, 2004, vol. 20, no. 3, p. 777-785.

THIMMARAJU, Rudrappa; BHAGYALAKSHMI, Neelwrne; NARAYAN, M.S. and RAVISHANKAR, G.Aswathanarayana. Food-grade chemical and biological agents permeabilize red beet hairy roots, assisting the release of betalaines. Biotechnology Progress, 2003a, vol.19, no. 4, p. 1274-1282.

THIMMARAJU, Rudrappa; BHAGYALAKSHMI, Neelwarne; NARAYAN, M.S. and RAVISHANKAR, G.Aswathanarayana. Kinetics of pigment release from hairy root cultures of Beta vulgaris under the influence of $\mathrm{pH}$, sonication, temperature and oxygen stress. Process Biochemistry, 2003b, vol. 38, no. 7, p. 1069-1076.

TORRES, Eduardo; TINOCO, Raunel and VAZQUEZDUHALT, Rafael. Biocatalytic oxidation of polycyclic aromatic hydrocarbons in media containing organic solvents. Water Science and Technology, 1997, vol. 36, no. 10, p. 37-44.

UOZUMI, N.; KATO, Y.; NAKASHIMADA, Y. and
KABAYASHI, T. Excretion of peroxidase from horseradish hairy root in combination with ion supplementation. Applied Microbiology and Biotechnology, 1992, vol. 37, p. 560-565.

UOZUMI, N. and KABAYASHI, T. Artificial seed production through hairy root regeneration. In: DORAN, Pauline M., eds. Hairy roots - culture and applications. Netherlands, Harwood Academic Publishers, 1997, p. 113121.

VEITCH, Nigel C. Horseradish peroxidase: a modern view of a classic enzyme. Phytochemistry, 2004, vol. 65, no. 3, p. 249-259.

WITITSUWANNAKUL, Rapepun; WITITSUWANNAKUL, Dhirayos; SATTAYSEVANA, Benjamaz and PASITKUL, Piyaporn. Peroxidase from Hevea brasiliensis bark: purification and properties. Phytochemistry, 1997, vol. 44, no. 2, p. 237-241.

XU, Tiefeng; ZHANG, Lie; SUN, Xiaofen; ZHANG, Hanming and TANG, Kexuan. Production and analysis of organic acids in hairy root cultures of Isatis indigotica Fort. (Indigo woad). Biotechnology and Applied Biochemistry, 2004, vol. 39, p. 123-128. 